\title{
The AGR-1 Irradiation - Objectives, Success Criteria and Risk Management
}

James M. Kendall

June 2006

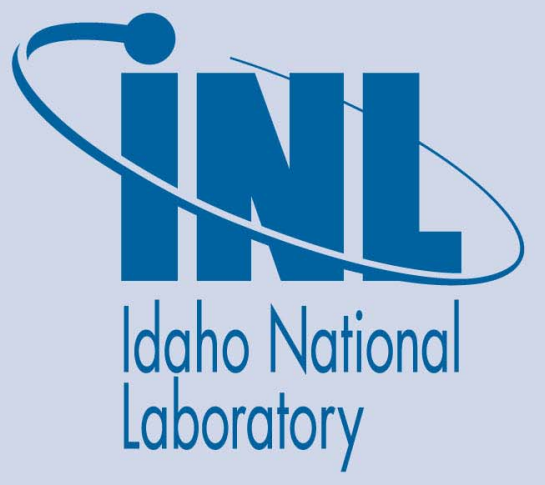

The INL is a U.S. Department of Energy National Laboratory operated by Battelle Energy Alliance 


\section{The AGR-1 Irradiation - Objectives, Success Criteria and Risk Management}

James M. Kendall

June 2006

Idaho National Laboratory
Idaho Falls, Idaho 83415

Prepared for the

U.S. Department of Energy

Office of Nuclear Energy

Under DOE Idaho Operations Office

Contract DE-AC07-05ID14517 


\section{EXECUTIVE SUMMARY}

The AGR-1 experiment being conducted by the US Department of Energy Advanced Gas Reactor Fuel Development and Qualification Program (AGR fuel program) will irradiate TRISO-coated particle fuel in compacts under conditions representative of a Very High Temperature Reactor (VHTR) core. The anticipated fuel performance requirements of a prismatic core VHTR significantly exceed established TRISO-coated particle fuel capability in terms of burnup, temperature and fast fluence. AGR-1 is the first in a planned series of eight irradiations leading to the qualification of low enriched uranium coated particle fuel compacts for service in a VHTR, as identified in an overall Technical Program Plan produced at the beginning of the program ${ }^{1}$. The AGR-1 experiment is scheduled for insertion in the Advanced Test Reactor (ATR) in the first quarter of fiscal year 2007 and to be irradiated for a period of up to approximately two and a half years. The irradiation rig, designated a "test train" is designed to provide six independently controlled (for temperature) and monitored (for fission product gas release) capsules containing fuel samples.

A major objective of the AFR fuel program is to establish the capability to independently control and monitor six capsules in a single ATR location for irradiation conditions representative of a VHTR. This capability is necessary to meet AGR fuel program cost and schedule constraints while supporting the primary elements of the Technical Program Plan: (1) selection of a reference fuel, (2) development and validation of fuel performance and fission product transport models, and (3) qualification of the reference fuel. It will also present an attractive fuel irradiation option for other US and international programs. However, the combination of functional requirements, space limitations and environmental conditions required of the test train presents difficult challenges for its design, fabrication and operation. This was recognized from the beginning, thus the AGR-1 irradiation test was included in the program plan as a shakedown test of a multi-capsule test train design to establish a proven capability for the subsequent planned irradiation tests. Design and fabrication of the test train is being conducted within a structured quality control environment in compliance with the requirements of NQA-1 (2000). The design has been subjected to formal reviews at each stage of development that, in combination with the efforts of the designers, has identified a comprehensive set of potential problems and failure modes which are being addressed in design and fabrication of the test train. Some of the more significant challenges are listed in this document along with design provisions incorporated to address them. In addition, operational contingencies that could be implemented should potential problems arise during the irradiation are discussed.

The last irradiation of US low enriched uranium TRISO-coated particle fuel (HRB-21), conducted in the early 1990s, substantially exceeded expected particle failure and fission product release levels. In the years following that irradiation, extensive efforts were undertaken to identify causes of the poor fuel performance and to establish the modifications to fuel property requirements and fabrication process conditions necessary to resolve the deficiencies. However, considerable uncertainty remained regarding production of a fuel that could exhibit the high level of performance required to support VHTR design requirements. Thus in reestablishing the capability to fabricate coated particle fuel in the US, the AGR fuel program has expended substantial effort to identify the fuel properties that are of primary importance for successful performance and to gain a better understanding of the relationships between process parameters and fuel properties. This has resulted in the fabrication of a baseline fuel considered to have the best prospects for meeting performance requirements, and three variants that address the areas of greatest uncertainty with respect to the performance of the baseline fuel.

Given the difficulties associated with the challenging test train design and the uncertainties associated with production of fuel capable of meeting the anticipated high VHTR performance requirements, it is anticipated that some problems will arise during final assembly and irradiation of AGR-1 and that there may be some surprises with respect to the performance of the fuel in AGR-1. However, the systematic 
and disciplined approach to the design of the test train and to the development of the test train assembly procedures provides a basis for confidence that the problems encountered will be limited and manageable. Likewise, the care taken in specifying and fabricating the AGR-1 baseline fuel, and in selecting the AGR1 fuel variants to provide diversity in areas of primary uncertainty, provides a basis for confidence that at least one of the fuel types will perform at a level approaching VHTR requirements. The primary objectives and multi-level success criteria for AGR-1 are addressed in this report. Complete success at all levels is possible, but partial success, in combination with the experience gained and information developed to date would still represent a significant advance in the state of the art of TRISO-coated particle fuel in the US. The fuel fabrication process developed for AGR-1 will be used to fabricate driver fuel for the fission product transport irradiations (AGR-3 and AGR-4); and the test train design, with adjustments and improvements based on the experience gained from AGR-1 fabrication and operation, will serve as the framework for the design, fabrication, and operation of test trains for future irradiations. Primary issues considered in the design, fabrication, and operation of the AGR-1 test train and in the selection and fabrication of the AGR-1 fuel, along with provisions for addressing the issues, are listed in Table ES-1 below.

Table ES-1 - Provisions for AGR-1 Design/Performance Issues

\begin{tabular}{|c|c|c|}
\hline Issue & Provision & Section/Page \\
\hline \multicolumn{3}{|c|}{ Test Train Design and Fabrication } \\
\hline Internal leakage & $\begin{array}{l}\text { Qualified brazing procedure, helium flow to } \\
\text { common gas volume }\end{array}$ & $5.1 / 13$ \\
\hline External leakage & $\begin{array}{l}\text { Quality assurance, ASME B31.1 and Section III } \\
\text { welds, helium leak check }\end{array}$ & $5.1 / 14$ \\
\hline $\begin{array}{l}\text { Differential thermal } \\
\text { expansion }\end{array}$ & $\begin{array}{l}\text { 3-D thermal and structural analyses, sliding } \\
\text { through-tube penetration }\end{array}$ & $5.1 / 14$ \\
\hline Thermocouple failures & $\begin{array}{l}\text { Testing of candidate thermocouples, diverse and } \\
\text { redundant thermocouples with selective placement }\end{array}$ & $5.1 / 14$ \\
\hline Gas line failures & Assembly mockups, flow checks & $5.1 / 14$ \\
\hline $\begin{array}{l}\text { Fission product monitor } \\
\text { failure }\end{array}$ & $\begin{array}{l}\text { A spare system that can be valved into any of the } \\
\text { capsules is provided }\end{array}$ & $5.1 / 14$ \\
\hline $\begin{array}{l}\text { Graphite fuel specimen } \\
\text { holder cracking }\end{array}$ & 3-D thermal and structure analyses & $5.1 / 15$ \\
\hline $\begin{array}{l}\text { Chemical attack of fuel test } \\
\text { articles }\end{array}$ & Capsule material selection and placement & $5.1 / 15$ \\
\hline $\begin{array}{l}\text { Temperature control during } \\
\text { irradiation }\end{array}$ & $\begin{array}{l}\text { Borated graphite in fuel specimen holder as } \\
\text { burnable poison to limit power variation }\end{array}$ & $5.1 / 15$ \\
\hline Axial power variation & $\begin{array}{l}\text { Location in ATR core, reduction in boron } \\
\text { concentrations in end capsules }\end{array}$ & $5.1 / 15$ \\
\hline Azimuthal power variation & Hafnium shield in $240^{\circ}$ sector facing ATR core & $5.1 / 15$ \\
\hline $\begin{array}{l}\text { Overpower during PALM } \\
\text { cycles }\end{array}$ & $\begin{array}{l}\text { He- } 3 \text { reduces period of concern, coordinated with } \\
\text { ATR operations }\end{array}$ & $5.1 / 15$ \\
\hline
\end{tabular}




\begin{tabular}{|c|c|c|}
\hline Issue & Provision & Section/Page \\
\hline $\begin{array}{l}\text { Test train contamination } \\
\text { following irradiation }\end{array}$ & $\begin{array}{l}\text { Procedure development to prevent moisture } \\
\text { intrusion during test train removal from ATR }\end{array}$ & $5.1 / 15$ \\
\hline \multicolumn{3}{|c|}{ Fuel Selection and Fabrication } \\
\hline $\begin{array}{l}\text { General fuel failure } \\
\text { mechanisms }\end{array}$ & $\begin{array}{l}\text { Development of fuel specifications, fabrication in } \\
\text { compliance with QA program }\end{array}$ & $5.2 / 17$ \\
\hline $\begin{array}{l}\text { Irradiation induced } \mathrm{PyC} \\
\text { dimensional changes }\end{array}$ & $\begin{array}{l}\text { IPyC coating condition/properties trade study, } \\
\text { baseline/variants } 1 \& 2 \text { diversity in IPyC } \\
\text { conditions/properties }\end{array}$ & $5.2 / 17$ \\
\hline Uranium dispersion & $\begin{array}{l}\text { Investigation in IPyC study, baseline/ } \\
\text { variants } 1,2 \& 3 \text { diversity in IPyC and SiC } \\
\text { conditions/properties }\end{array}$ & $5.2 / 17$ \\
\hline $\begin{array}{l}\text { Diffusive release of } \\
\text { metallic fission products }\end{array}$ & $\begin{array}{l}\text { Diversity of } \mathrm{SiC} \text { microstructure between baseline/ } \\
\text { variants } 1 \& 2 \text { and variant } 3\end{array}$ & $5.2 / 17$ \\
\hline SiC anomalies & $\begin{array}{l}\text { Specification reduction in defect fraction relative } \\
\text { to prior fuels, process development to meet spec. }\end{array}$ & $5.2 / 18$ \\
\hline Impurity attack of SiC layer & $\begin{array}{l}\text { Limit impurities in kernel, compact and graphite } \\
\text { fuel holder }\end{array}$ & $5.2 / 18$ \\
\hline Kernel migration & $\begin{array}{l}\text { UCO kernel, analysis to demonstrate acceptability } \\
\text { of nonconformance with } \mathrm{C} / \mathrm{U} \text { specification }\end{array}$ & $5.2 / 18$ \\
\hline Pressure vessel failure & $\begin{array}{l}\text { UCO kernel, analysis to demonstrate acceptability } \\
\text { of nonconformance with } \mathrm{C} / \mathrm{U} \text { specification }\end{array}$ & $5.2 / 18$ \\
\hline \multicolumn{3}{|c|}{ Operational Contingencies } \\
\hline $\begin{array}{l}\text { Drift of thermocouple } \\
\text { indication within a capsule }\end{array}$ & $\begin{array}{l}\text { Use 3D thermal analysis, out-of-pile test results, } \\
\text { multiple capsule thermocouple indications and } \\
\text { trends to quantify. Apply bias if being used as a } \\
\text { control thermocouple }\end{array}$ & $6 / 19$ \\
\hline $\begin{array}{l}\text { Failure of thermocouple } \\
\text { within a capsule }\end{array}$ & $\begin{array}{l}\text { Use 3D thermal analysis, remaining thermocouple } \\
\text { indications, and prior capsule temperature data for } \\
\text { continued temperature distribution. If a control } \\
\text { thermocouple, switch to functioning thermocouple } \\
\text { with adjustment to setpoint }\end{array}$ & $6 / 19$ \\
\hline $\begin{array}{l}\text { Failure of all thermocouples } \\
\text { within a capsule }\end{array}$ & $\begin{array}{l}\text { Use 3D thermal analysis, prior capsule } \\
\text { temperature data, and temperature indications in } \\
\text { adjacent capsules for continued temperature } \\
\text { distribution. Switch to manual control, use data } \\
\text { from capsule fission product monitor for } \\
\text { confirmation as appropriate. }\end{array}$ & $6 / 19$ \\
\hline $\begin{array}{l}\text { Change in test train internal } \\
\text { leakage }\end{array}$ & $\begin{array}{l}\text { Detect by monitoring common gas space and } \\
\text { capsule flows and pressures. Adjust gas flows to } \\
\text { common space and affected capsule as necessary } \\
\text { to mitigate and prevent cross-contamination. }\end{array}$ & $6 / 19$ \\
\hline
\end{tabular}




\begin{tabular}{|l|l|c|}
\hline \multicolumn{1}{|c|}{ Issue } & \multicolumn{1}{c|}{ Provision } & Section/Page \\
\hline Capsule gas line failure & $\begin{array}{l}\text { Mitigation actions, in terms of adjustments to } \\
\text { capsule and common space gas flow, and the } \\
\text { impact of the failure would depend on the extent } \\
\text { and location of the leak. }\end{array}$ & $6 / 20$ \\
\hline $\begin{array}{l}\text { Excessive fuel failures } \\
\text { within a capsule }\end{array}$ & $\begin{array}{l}\text { Monitor for indications of cross-contamination in } \\
\text { other capsules. If necessary, increase helium } \\
\text { fraction to affected capsule, decrease gas supply } \\
\text { flow to affected capsule, and/or increase helium } \\
\text { flow to common gas space. }\end{array}$ & $6 / 20$ \\
\hline
\end{tabular}




\section{TABLE OF CONTENTS}

$\underline{\text { Title }}$

Page

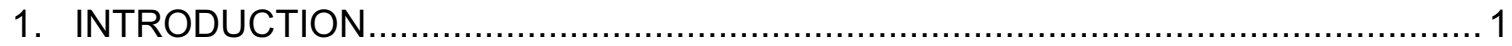



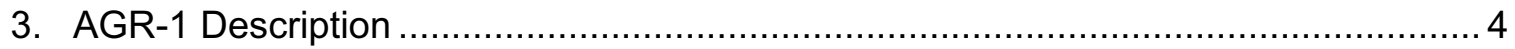

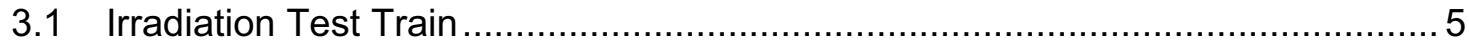

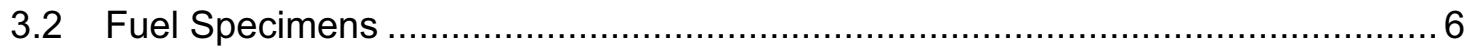

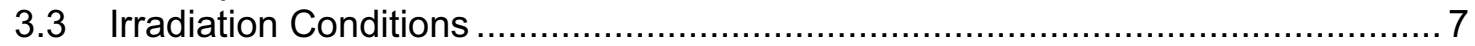

4. AGR-1 Objectives and Success Criteria ......................................................... 11

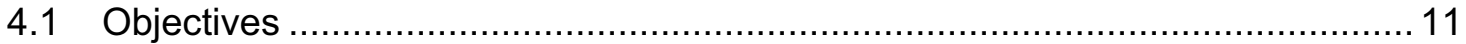

4.1.1 Test Train Design, Fabrication and Operation.................................. 11

4.1.2 Fuel Fabrication and Performance ................................................ 11

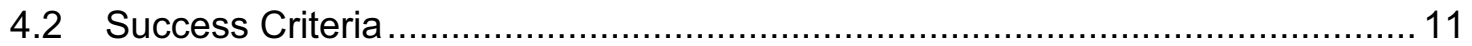

4.2.1 Test Train Design, Fabrication and Operation.................................. 12

4.2.2 Fuel Fabrication and Performance ................................................ 12

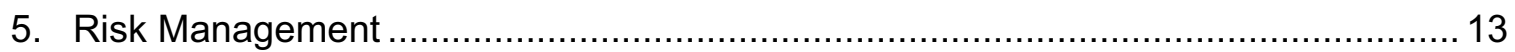



5.2. Fuel Selection and Fabrication ............................................................ 16

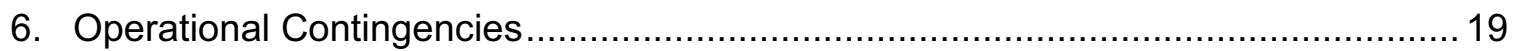






\section{LIST OF FIGURES}

$\underline{\text { Title }}$

Page

Figure 3-1. Advanced Test Reactor Plan View ............................................................ 4

Figure 3-2. AGR Irradiation Test Train ...................................................................... 5

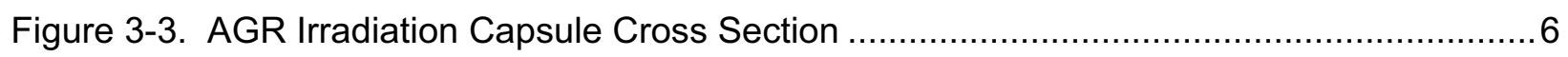

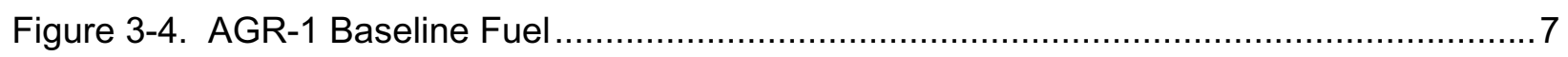

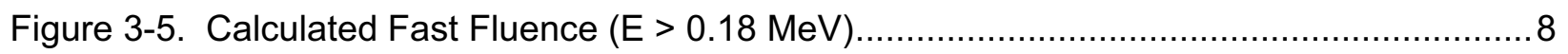

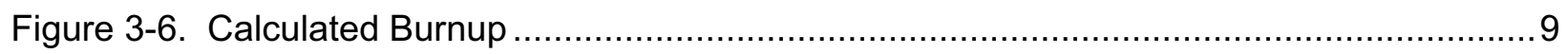

Figure 3-7. Volume and Time Averaged Fuel Temperature ........................................... 9

Figure 3-8. Temperature $\left({ }^{\circ} \mathrm{F}\right)$ in Graphite Holder, Capsule 4, 280 EFPD ............................ 10

Figure 3-9. Temperature ( ${ }^{\circ}$ F), Fuel Stack 3, Capsule 4, 280 EFPD ................................ 10 


\section{ACRONYMS}

AGR advanced gas reactor

ATR Advanced Test Reactor

BWXT BWX Technologies (formerly B\&W)

DOE U.S. Department of Energy

$\mathrm{DUO}_{2} \quad$ depleted $\left(<0.71 \%{ }^{235} \mathrm{U}\right)$ uranium dioxide

GT-MHR Gas-Turbine Modular Helium Reactor (Brayton-cycle plant)

HTGR high-temperature gas-cooled reactor (a steam-cycle plant)

INL Idaho National Laboratory

IPyC inner pyrolytic carbon

LEU low-enriched uranium

LEU UCO low-enriched $\left(0.71 \%<{ }^{235} \mathrm{U}\right.$ content $\left.<20 \%\right)$ uranium mixture of $\mathrm{UO}_{2}$ and $\mathrm{UC}_{2}$ herein referring to $19.9 \%{ }^{235} \mathrm{U}$ unless otherwise specified

NE DOE Office of Nuclear Energy, Science, and Technology

NQA Nuclear Quality Assurance

NUCO natural $\left(0.71 \%{ }^{235} \mathrm{U}\right)$ uranium mixture of $\mathrm{UO}_{2}$ and $\mathrm{UC}_{2}$

OPyC outer pyrolytic carbon coating in a TRISO particle

ORNL Oak Ridge National Laboratory

PyC pyrolytic carbon

$\mathrm{SiC} \quad$ silicon carbide

TRISO A multilayer coating, on a spherical kernel, made up of a low-density pyrocarbon (buffer) layer surrounded by an IPyC, surrounded by a $\mathrm{SiC}$, surrounded by an $\mathrm{OPyC}$

$\mathrm{UCO}$ mixture of $\mathrm{UO}_{2}$ and $\mathrm{UC}_{2}$

US United States

VHTR Very High Temperature Reactor 


\section{INTRODUCTION}

The irradiation test train that is being designed and fabricated for AGR-1 will provide the capability to irradiate fuel in six individually controlled (for temperature) and monitored (for temperature and fission product gas release) capsules within a single location in the Advanced Test Reactor (ATR). This capability will allow the simultaneous irradiation and monitoring of up to six different fuel types or of a single fuel type at up to six different temperatures, or a combination of temperatures and fuel types. In the early phase of the Advanced Gas Reactor Fuel Development and Qualification Program (AGR fuel program), this capability will be used to irradiate multiple fuel types in irradiation tests AGR-1 and AGR2 in order to strengthen the understanding of the relationships among fuel process conditions, fuel properties and irradiation performance; and to support the selection of a reference fuel for qualification. It will also efficiently support fission product transport model development by allowing irradiation of a single fuel type at varying temperatures in irradiation tests AGR-3 and AGR-4. In the later phase of the program, the multicapsule capability will support irradiation of a single fuel type at varying temperatures to support fuel qualification (AGR-5 and AGR-6), and to demonstrate fuel performance margins and validate fuel performance and fission product transport models (AGR-7 and AGR-8). This multicapsule capability parallels the capability established in the Petten reactor (European Union) and the IVV-2M reactor (Russian Federation), enhancing the international status of the ATR as a high temperature reactor fuel irradiation facility.

A primary objective of the AGR-1 irradiation is the shakedown of the multi-capsule test train design. Establishment of this multi-capsule irradiation capability is essential for execution of the AGR fuel program and it will also provide an attractive option for high temperature reactor fuel irradiation by other US or international programs. The irradiation is planned to begin in the first quarter of FY 2007 and continue for up to two and a half years. This report provides an overview of the AGR-1 irradiation, which is the first of a series of eight irradiations planned for the AGR fuel program. The development of an overall plan for the program and the context for the AGR-1 irradiation are briefly summarized in a background discussion in section 2 .

Section 3 provides a summary description of the AGR-1 irradiation, including location in the ATR and the in-reactor and ex-reactor components of the test train. Fuel types included in the six capsules are discussed along with predicted irradiation conditions.

A set of objectives for the design, fabrication and operation of the AGR-1 test train and for the selection and fabrication of the fuel are described in section 4. These objectives form the basis for a set of progressively more challenging success criteria for the test train and for the fuel.

Section 5 describes the steps taken to manage and mitigate the risks presented by the AGR-1 test train and fuel, with regard to meeting the objectives discussed earlier. The test train is addressed in terms of potential problems that are likely to be encountered by a first-of-a-kind design under the challenging constraints and conditions of AGR-1, and the design provisions that have been included to mitigate these problems. Fuel is addressed in terms of the specification and fabrication of the baseline fuel and variants to maximize the potential for successful performance of at least one fuel type.

Section 6 discusses contingency options for mitigation of problems that could be encountered in the course of AGR-1 operation. The problems considered include both failures of test train components and excessive fuel failures within one or more capsules. 


\section{BACKGROUND}

The first major effort of the AGR Fuel Development and Qualification Program was a detailed technical planning activity to identify the scope required to develop and qualify a TRISO-coated particle fuel that could meet the operational and safety requirements of a very-high-temperature gas-cooled reactor (VHTR). In the absence of a VHTR reactor design, the fuel requirements were drawn from preconceptual design documentation for the Gas Turbine Modular Helium Reactor (GT-MHR). In an initial meeting at Idaho National Laboratory (INL) in May 2002, working groups were formed in the areas of fuel manufacture, fuel and materials irradiation, safety testing and postirradiation examination, fuel performance modeling, and fission product transport and source term. Each working group drafted a portion of Revision 0 of the Technical Program Plan ${ }^{1}$. The drafts were reviewed and discussed in a meeting at Oak Ridge National Laboratory (ORNL) in August 2002, leading to an initial draft of the overall plan. In those discussions, the challenge of designing and fabricating a multi-capsule fuel irradiation test train to be inserted in ATR and the potential for problems with operation of a first-of-akind design were recognized. Thus it was agreed that the primary objective of the first irradiation, designated AGR-1, would be to shake down the test train, i.e., test the AGR-1 capsules, test train and pertinent equipment under operating conditions to determine possible faults and defects, and to familiarize the ATR staff with its operation and control.

AGR-1 was identified as a "shakedown/early fuel" irradiation, and considerations associated with including a shakedown irradiation in the series of irradiations to be conducted were discussed in section D. 4 of the Technical Program Plan ${ }^{1}$. The AGR-1 test, as envisioned in revision 0 of the plan, was described as follows (bold text added to illustrate important elements changed in revision $1^{2}$ ):

This multicell capsule will include compacts made from early small-coater particles, possible compacts made from German particles, as well as possible unbonded particles and material samples. This will provide experience with multicell capsule design, fabrication, and operation, and it will reduce the chances of capsule or cell failures in subsequent capsules. If successfully taken to a substantial fraction of design burnup and fast fluence, it will provide early data on irradiated fuel performance. These early data on performance of fuel variants would support the development of a fundamental understanding of the relationship between the fuel fabrication process and fuel product properties and irradiation performance.

The approach envisioned was to include early small-coater particles and possibly German particles primarily as a prototypical heat source for the shakedown of the irradiation test train. Limited characterization of the early particles was envisioned to minimize cost and schedule.

As fuel development work progressed in conjunction with implementation of NQA-1 (2000) quality assurance requirements, the objective related to the development of a better understanding of the relationship between aspects of the fuel fabrication process, fuel product properties and irradiation performance took on a greater importance. This led to the development of a rigorous full scope characterization capability to assess compliance with a detailed specification for AGR-1 fuel ${ }^{3}$. The AGR1 irradiation description was adjusted in revision 1 of the Technical Program Plan ${ }^{2}$ to read as follows (bold text added to illustrate important elements changed in revision 1):

This multi-monitor test train will include compacts made from particles produced in a smallcoater in conjunction with fuel process development. This irradiation will provide experience with multi-monitor test train design, fabrication, and operation, and will reduce the chances of test train or capsule failures in subsequent test trains. If successfully taken to a substantial fraction of design burnup and fast fluence, it will provide data on irradiated fuel performance for baseline and fuel variants selected based on data from fuel process development and existing irradiation experience. These early data on performance of fuel variants could support the selection of a reference fuel as well as development of fundamental understanding of the 
relationship between the fuel fabrication process, fuel product properties, and irradiation performance.

In addition to the substantial changes bolded above, the nomenclature was changed (cell to capsule and capsule to test train) to achieve a definition consistent with conventional ATR terminology throughout program documentation.

In the original plan, program participants hoped to obtain some limited fuel performance data from AGR-1 (albeit as a second priority for the irradiation), but development of a fundamental understanding of the relationship between the fuel fabrication process, fuel product properties, and irradiation performance was considered to be primarily part of the scope of the coating scaleup activities culminating in the AGR-2 irradiation test. However, given the technical challenges associated with scaleup of the fabrication process, the AGR fuel program decided that obtaining early data from AGR-1 fuel fabrication and irradiation to demonstrate the viability of using German-type coatings on UCO kernels and to enhance the understanding of the relationship between the fuel fabrication process, the fuel product properties, and irradiation performance would be highly desirable. These changes substantially expanded the scope of fuel fabrication and characterization methods development required for the production of AGR-1 fuel. They also substantially expanded the potential value of the results of the AGR-1 irradiation, placing greater emphasis on performance of the fuel, which will help guide process development efforts and fuel specification evolution during coating scaleup and fabrication of the AGR-2 fuel. Thus while the shakedown of the test train design remains a primary objective, the objective of producing fuel performance data of value for reference fuel selection and for improving the understanding of coated particle fuel performance has greatly increased in importance. It is also now intended that the AGR-1 irradiation will provide irradiated samples for early safety testing (i.e., accident condition simulation tests) with results to be used in making a decision to proceed with fabrication of qualification test fuel for irradiation tests AGR-5 and AGR-6 prior to the availability of safety test data from AGR-2. 


\section{AGR-1 DESCRIPTION}

The AGR-1 irradiation is expected to begin in the first quarter of FY07 and, if totally successful, to continue for approximately two and a half years. The irradiation will be conducted in the ATR reactor at the Idaho National Laboratory in the B-10 irradiation location in the beryllium reflector, one of the large "B" holes as indicated in Figure 3-1. The in-reactor components of the experiment, designated the irradiation test train, will provide a thermal and materials irradiation environment representative of that in a high temperature gas-cooled reactor (HTGR) core. In addition, the experiment will be placed in a position within the ATR where the neutron spectrum is representative of HTGR conditions. This is important because irradiation performance depends upon both the fast fluence, which affects material properties and behavior, and the thermal fluence, which determines the fuel burnup. Furthermore, past US irradiations have been substantially accelerated in fast and thermal fluence, which can have a deleterious impact on fuel performance. Thus for the AGR program, irradiations will be much closer to real time to minimize the potential for poor fuel performance because of acceleration effects.



Figure 3-1. Advanced Test Reactor Plan View. 


\subsection{Irradiation Test Train}

The AGR-1 irradiation test train, shown in Figure 3-2, will contain six individual stainless steel enclosed capsules, each approximately 1-3/8 inches $(35 \mathrm{~mm})$ in diameter and 6 inches $(152 \mathrm{~mm})$ long. The capsules will be welded end to end to form a cylinder 36 inches $(914 \mathrm{~mm})$ long. A spacer and end cap attached to the bottom will result in a total assembled length of approximately 43 inches (1092 mm). A lead-out tube attached to the top will hold the assembly in position in the ATR core and contain and protect the gas lines and thermocouples extending from the test train to the reactor penetration. Each capsule will contain twelve fuel compacts that are approximately $0.5 \mathrm{in} .(12.7 \mathrm{~mm})$ in diameter by $1 \mathrm{in}$. $(25.4 \mathrm{~mm})$ long. Each capsule will be independently supplied with a flowing mixture of helium and neon gases, which have substantially different thermal conductivities. Temperature control for each capsule will be accomplished by adjusting the mixture ratio of the two gases. Temperature control gas exhaust lines will transport fission products released from the fuel compacts within a capsule to the fission product monitor for that capsule, which will be capable of detecting individual particle failures, up to at least 250 particle failures in a single capsule, and measuring the rate of release of specific gaseous isotopes of interest. If required, He-3, which has a very large thermal neutron absorption cross section, can be used to limit power and temperature during an occasional higher power operating mode of the ATR referred to as a PALM cycle.



Figure 3-2. AGR Irradiation Test Train.

A cross section of a capsule in the test train is shown in Figure 3-3. The thermocouples and gas lines for lower capsules are routed in "through-tubes". These tubes are brazed to the capsule top plate and penetrate the capsule bottom plate via a sliding seal. Gas line and thermocouple lead penetrations are 
brazed to the capsule top plate. The gas supply line terminates near the bottom of the capsule while the return line terminates near the top to facilitate sweeping of the capsule with the helium/neon gas mixture. Multiple thermocouples are provided for each capsule, with junction locations varying axially and radially, and differing thermocouple types located in accordance with their temperature limitations. Flux wires and melt wires will be encapsulated in vanadium and inserted into each graphite fuel holder from the bottom.



Figure 3-3. AGR Irradiation Capsule Cross Section.

\subsection{Fuel Specimens}

All of the fuel particles and compacts within a given capsule have been fabricated to the same specification. The contents of each of the capsules, numbered consecutively from the bottom to the top, will be as follows (all variant specifications will be identical to baseline fuel with the exceptions noted below):

- $\quad$ Capsule 6 - Baseline fuel specified with the intent of maximizing the prospects of successful performance.

- Capsule 5 - Variant 1 fuel containing an inner pyrocarbon layer produced at an increased temperature. 
- Capsule 4 -Variant 3 fuel containing a silicon carbide layer produced at a reduced temperature with a mixture of argon and hydrogen.

- $\quad$ Capsule 3 - Baseline fuel.

- Capsule 2 - Variant 2 fuel containing an inner pyrocarbon layer produced with an increased coating gas ratio.

- Capsule 1 - Variant 3 fuel.

Representative cross sections from each of the four batches comprising the baseline fuel particle composite are shown in Figure 3-4 a. Dimensional checking of a baseline fuel compact is shown in Figure 3-4 b. Sufficient quantities of particles and compacts for each type were produced to allow for characterization requirements, loading the capsule, spares, and archived material.
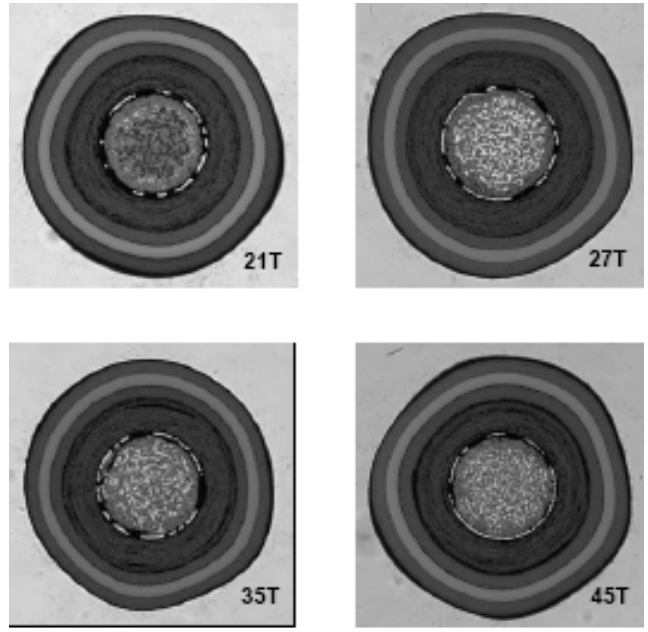

a. Particle Cross Sections

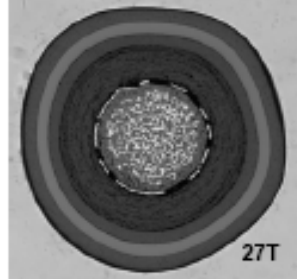

b. Compact Dimension Measurement

Figure 3-4. AGR-1 Baseline Fuel.

Additional definition and discussion of the rationale behind the selection of the fuel types for the six capsules is addressed in section 6.2.

\subsection{Irradiation Conditions}

In the absence of a Next Generation Nuclear Plant (NGNP) design and core temperature analyses, and recognizing that the NGNP program has chosen the GT-MHR design as the starting point for further reactor development, GT-MHR design service conditions were used to establish the AGR-1 irradiation conditions. The following irradiation conditions are specified for AGR-1 ${ }^{4}$ :

- The instantaneous peak temperature for each capsule shall be $\leq 1400{ }^{\circ} \mathrm{C}$.

- The time average, peak temperature for each capsule shall be $\leq 1250{ }^{\circ} \mathrm{C}$.

- The time average, volume average temperature for each capsule shall be $1150+30 /-75^{\circ} \mathrm{C}$. 
- The minimum compact average burnup for each fuel compact shall be $>14 \%$ FIMA.

- The compact average burnup goal for the majority of the fuel compacts should be $>18 \%$ FIMA.

- The maximum peak fast neutron fluence for each fuel compact shall be $<5 \times 10^{25} \mathrm{n} / \mathrm{m}^{2}, \mathrm{E}>0.18$ $\mathrm{MeV}$.

- The minimum peak fast neutron fluence for each fuel compact shall be $>1.5 \times 10^{25} \mathrm{n} / \mathrm{m}^{2}, \mathrm{E}>0.18$ $\mathrm{MeV}$.

- The instantaneous peak power per particle shall be $\leq 400 \mathrm{~mW} /$ particle.

Detailed 3-D neutronics and thermal models of the in-core portion of the AGR-1 test train were developed to support the experiment design. Representative results of design calculations of irradiation conditions for AGR-1 are shown in Figures 3-5 through 3-9. A pretest prediction will be performed prior to beginning the irradiation utilizing the final fuel compact and capsule parameters. Pretest predictions will also include calculation of fuel behavior using the INL fuel performance code, PARFUME. The neutronics, thermal and fuel performance models will also be available to support the operation of AGR-1.

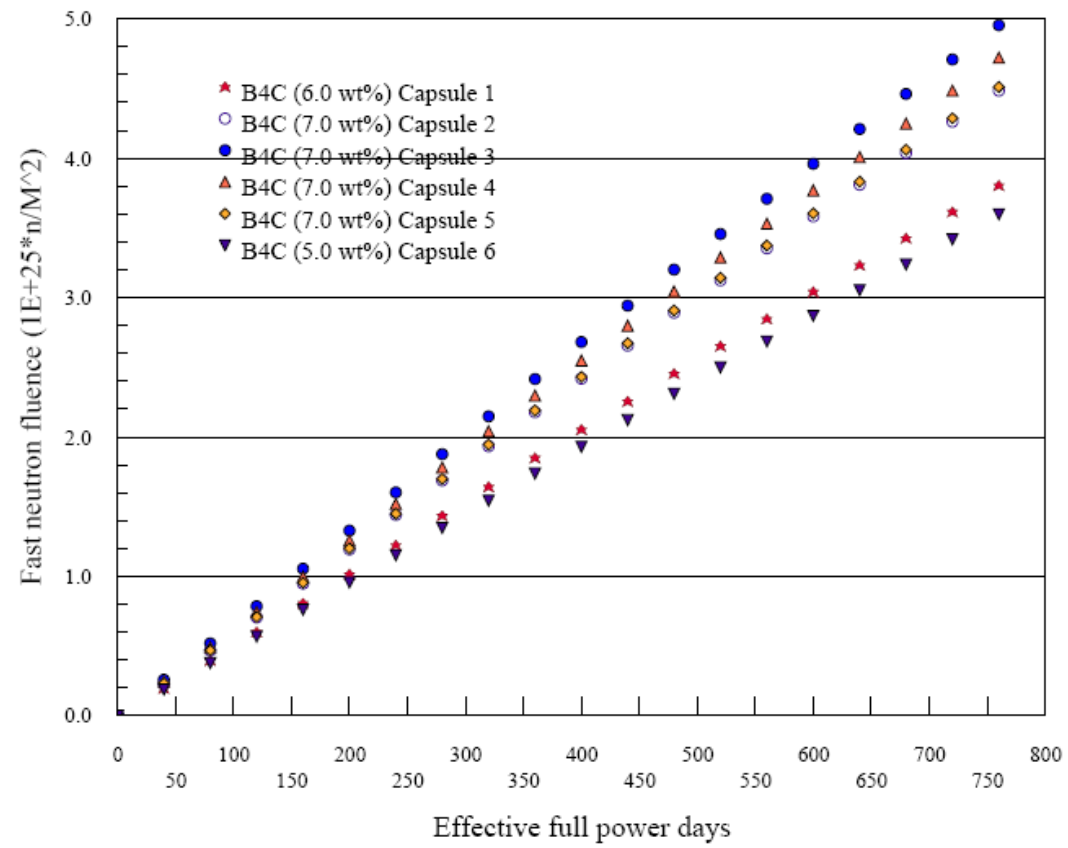

Figure 3-5. Calculated Fast Fluence (E > 0.18 MeV). 


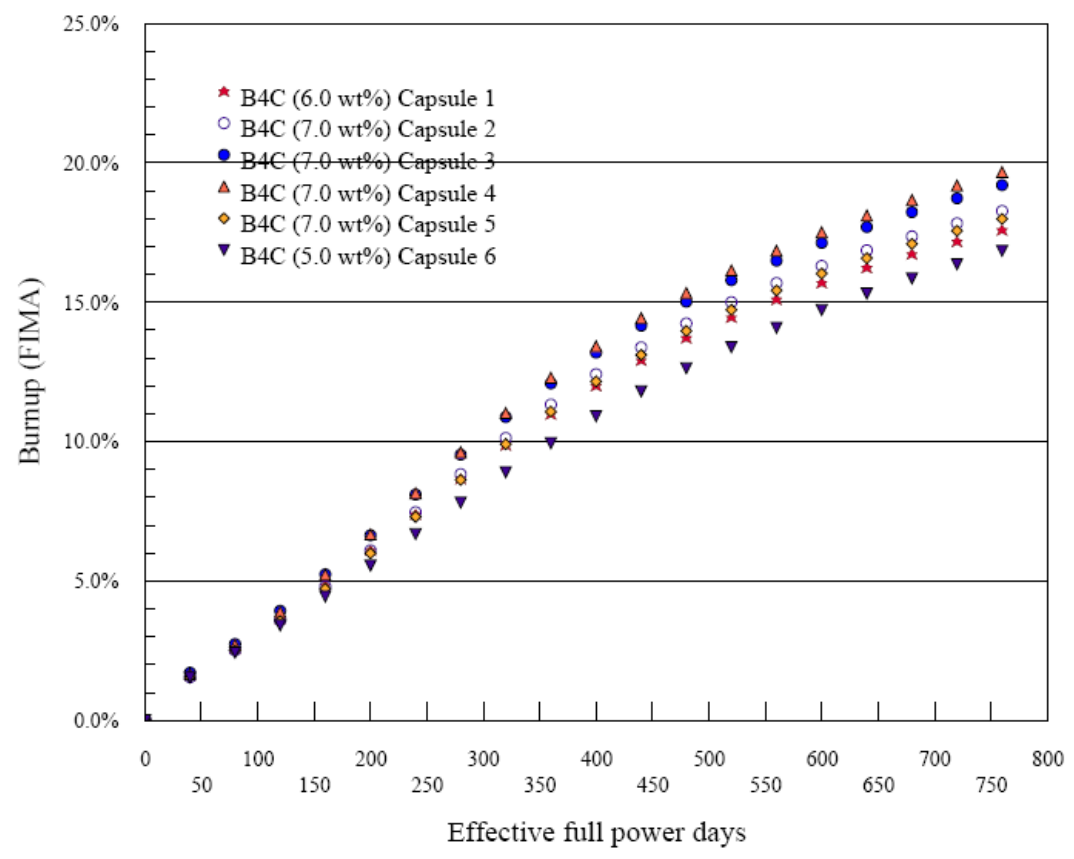

Figure 3-6. Calculated Burnup.

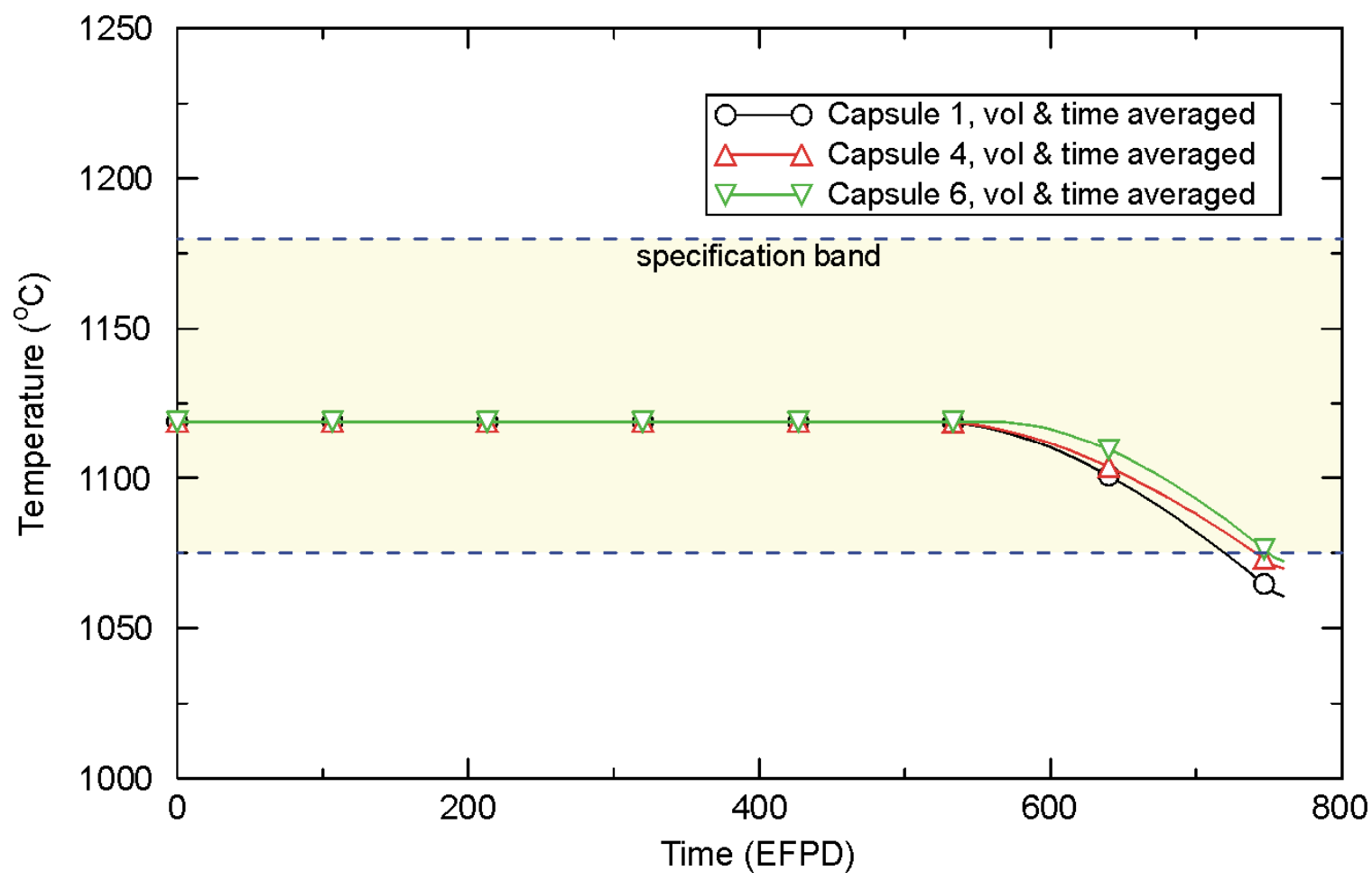

Figure 3-7. Volume and Time Averaged Fuel Temperature . 


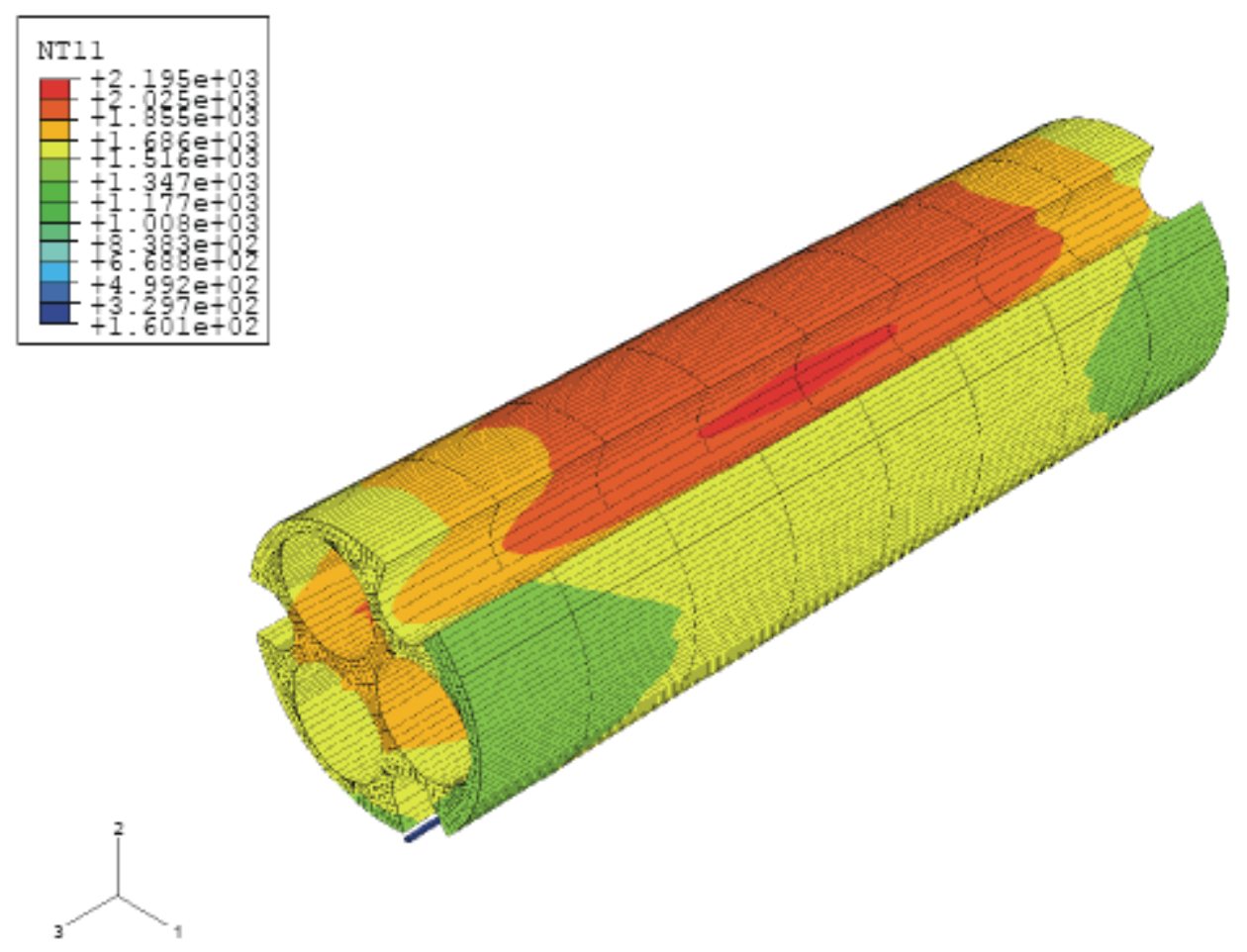

Figure 3-8. Temperature ( $\left.{ }^{\circ} \mathrm{F}\right)$ in Graphite Holder, Capsule 4, 280 EFPD.
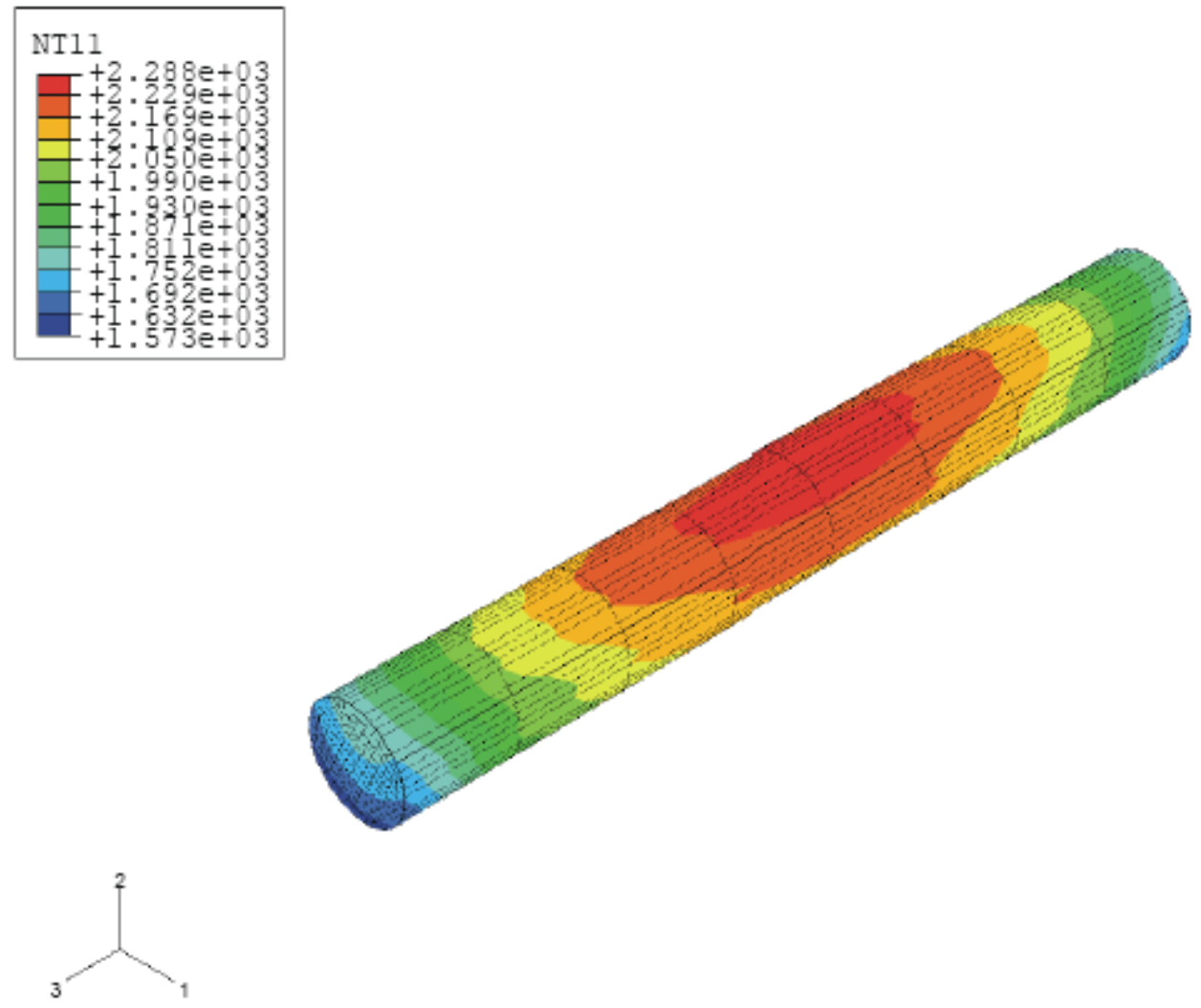

Figure 3-9. Temperature ( $\left.{ }^{\circ} \mathrm{F}\right)$, Fuel Stack 3, Capsule 4, 280 EFPD. 


\section{AGR-1 OBJECTIVES AND SUCCESS CRITERIA}

As noted earlier, AGR-1 is directed toward irradiation test train design, fabrication, and shakedown operation, plus gaining fuel fabrication experience and irradiation data with small coater fuel. The major objectives and related success criteria for the test train and fuel are provided in this section.

\subsection{Objectives}

\subsubsection{Test Train Design, Fabrication and Operation}

Detailed technical and functional requirements for the AGR-1 experiment were developed and documented $^{5,6}$ Test train design and fabrication address the following major objectives:

- Provide multiple independently controlled and monitored fuel capsules

- For each capsule, provide an environment representative of VHTR service conditions

- Thermal (temperatures within specified limits)

- Chemical (helium/neon gas mixture, impurity levels and moisture levels within specified limits, protect fuel compacts from migration of elements from metallic capsule components)

- Neutronics (local power within specified limits, with representative neutron energy spectrum)

- Maintain integrity for a sufficient duration to achieve specified fuel burnup and fast fluence targets

- Protect the fuel test articles during fabrication, insertion, irradiation, removal and disassembly of the test train.

\subsubsection{Fuel Fabrication and Performance}

Detailed specifications for the fuel types to be included in AGR-1 were developed and documented ${ }^{3}$. The specification and fabrication of AGR-1 fuel address the following major objectives:

- Produce a baseline fuel with characteristics selected to maximize potential for successful irradiation performance based on existing fuel performance data

- Produce variant fuels with characteristics selected to address major uncertainties in the performance of the baseline fuel

- Characterize baseline and variant fuels to demonstrate compliance with as-manufactured quality requirements

- Demonstrate maintenance of fuel integrity and retention of gaseous and metallic fission products to levels approaching anticipated VHTR requirements for normal operation and accident conditions in at least one fuel type.

\subsection{Success Criteria}

A series of success criteria are defined below that represent an increasing level of success for the AGR-1 irradiation in terms of test train shakedown and fuel performance. The criteria are limited to in-pile

\footnotetext{
" The term "fission product" is intended to include fission product daughters and activation products.
} 
operation and test train disassembly and inspection, not including postirradiation examination and safety testing of the fuel, which will be defined later.

\subsubsection{Test Train Design, Fabrication and Operation}

1. Insertion of the test train in ATR and startup with normal indications on all measured parameters. (partial test train shakedown)

2. Operation through at least the first two ATR cycles, with subsequent termination and removal from ATR because of test train limitations that can be resolved by defined design modifications. (partial test train shakedown)

3. Operation through the first half of the planned duration, with subsequent termination and removal from ATR because of test train limitations that can be resolved by defined design modifications. (test train shakedown)

4. Operation for the planned duration with identified test train limitations that can be resolved by defined design modifications. (test train shakedown plus partial design validation)

5. Operation for the planned duration meeting the AGR-1 test specification requirements ${ }^{4}$, and successful removal of the test train from ATR without damage to the contents. (test train design validation)

\subsubsection{Fuel Fabrication and Performance}

1. Production of baseline and variant fuel test articles meeting AGR-1 specification requirements with minor exceptions addressed by nonconformance reports. (reestablishment of fuel fabrication capability)

2. Initial operation of one or more capsules with $\mathrm{Kr}^{85 \mathrm{~m}} \mathrm{R} / \mathrm{B} \leq 2.0 \times 10^{-6}$. (confirmation of initial fuel quality as determined by gaseous fission product retention)

3. Operation of one or more capsules beyond a fast fluence of $1.5 \times 10^{25} \mathrm{n} / \mathrm{m}^{2}$ with $\mathrm{Kr}^{85 \mathrm{~m}} \mathrm{R} / \mathrm{B} \leq$ $4.0 \times 10^{-6}$ and $\leq 5$ particle failures as indicated by spikes in the gross fission product monitor output. (indication of successful mitigation of irradiation shrinkage induced failures)

4. Operation of one or more capsules to burnup $\geq 15 \%$ FIMA with $\mathrm{Kr}^{85 \mathrm{~m}} \mathrm{R} / \mathrm{B} \leq 4.0 \times 10^{-6}$ and $\leq 5$ particle failures as indicated by spikes in the gross fission product monitor output. (confirmation of fuel performance as determined by gaseous fission product retention)

5. Postirradiation metallic fission product release and safety test performance criteria to be developed in conjunction with detailed planning of the postirradiation examination and safety testing activities. (confirmation of fuel performance as determined by metallic fission product retention) 


\section{RISK MANAGEMENT}

Design and fabrication of the AGR-1 test train present many technical challenges that could cause problems during fabrication, insertion, startup, operation and withdrawal. In order to maximize the amount of fuel contained in a capsule to meet statistical requirements for later irradiations, three columns of 0.5 inch $(12.7 \mathrm{~mm})$ diameter fuel compacts are placed in a triangular array within a cylinder with an outer diameter of $13 / 8$ inches $(35 \mathrm{~mm})$. The addition of gas supply and return lines, multiple thermocouples and fluence monitors for each individual capsule within the limited available space presents difficult design, fabrication and assembly challenges. Test train assembly involves brazing gas lines, thermocouple leads and thru tubes to capsule top heads, and welding together individual capsules to form the pressure boundary with an absolutely straight configuration to allow for proper insertion, operation and removal. Routing of thermocouple leads and gas lines through the stacked capsules that form the test train must be accomplished without damage during assembly. The AGR-1 irradiation duration and operating environment exceeds the proven capability of commercially available thermocouples. Differential thermal expansion associated with dissimilar materials and large temperature variations within capsules must be accommodated.

HRB-21, the most recent US low enriched uranium (LEU) coated particle fuel irradiation, substantially exceeded expected particle failure and fission product release levels ${ }^{7,8}$. Following production of the HRB-21 fuel in the late 1980s, no LEU coated particle fuel had been fabricated in the US, and the fuel production facility in which the HRB-21 fuel was fabricated was dismantled. It had also been generally recognized that performance of TRISO-coated particle fuel at the levels required for current reactor designs cannot be inferred from established product characterization methods alone. Thus, production of the AGR-1 fuel required re-establishment of US fuel fabrication and characterization capability without clear definition of the process conditions and product characteristics that would lead to successful fuel performance.

The extent of the challenges presented has been recognized by AGR program participants during the planning and conduct of work leading up to the AGR-1 irradiation. Actions taken by the AGR fuel program to identify and manage these risks and maximize the prospects for successful results from AGR1 are summarized below.

\subsection{Test Train Design and Fabrication}

Test train design, fabrication and operational challenges were recognized during initial program planning, and were the basis for identifying shakedown of the test train design as a primary objective of AGR-1. Many of the potential problems that might be encountered were identified in discussions regarding the need for a shakedown capsule, as noted in section B.4.3 of the original plan ${ }^{1}$ and subsequently during multiple test train design reviews. Potential test train limitations and failure modes, and provisions for addressing them are noted below.

- Internal leakage - A failure in a brazed capsule penetration could lead to leakage from the capsule into the common gas volume within the test train. This leakage could cause cross contamination of the capsule exhaust gas and loss of individual monitoring capability. To address this concern, , extensive development efforts have been directed toward qualifying brazing methods to produce high quality and high integrity brazes for the capsule penetrations. Also, the common gas volume comprised of the spaces between capsules, inside the capsule through-tubes and the lead-out tube has been designed so it can be supplied with helium held at a pressure slightly higher than the pressure in the capsules. Thus leakage would be pure helium into the capsules and crosscontamination would be avoided. 
- External leakage - A leak in the external pressure boundary would allow moisture to enter the test train. If the leak occurs in the space between capsules, e.g. in a circumferential weld joining the capsules, all of the test train components could be exposed to high moisture levels. With extensive use of refractory metals to withstand elevated temperatures and protect the fuel specimens from chemical attack, high moisture levels would rapidly degrade the test train capability. The limited space precludes use of a double containment for the test train, so the test train pressure boundary must be fabricated to a very high quality level. A new automated welder will be used to perform the capsule welds and extensive mockups and test welds were performed to qualify the equipment and procedure. All of the welds will be visually inspected and subjected to liquid penetrant testing to assure weld integrity and the assembly will be helium leak checked. All of these welds will meet the requirements of ASME Boiler and Pressure Vessel Code Section 3 Class III welds. Experiment safety analyses will include leaks in the pressure boundary to assure that they would not present a safety concern.

- Differential thermal expansion - Differential thermal expansion resulting from dissimilar materials and temperature variations within the test train can produce high localized stresses and cyclic conditions that can lead to component distortion or failure. Detailed thermal and stress analyses of the design were performed to identify and assess potential problem areas. The through-tubes that penetrate the capsules and serve as conduits for routing of gas lines and thermocouple leads were identified as having high stresses if brazed at both ends of the capsule. To address this concern the tubes will only be brazed at the top and will pass though low clearance openings at the bottom. In addition, the use of Mo for the through-tubes, a high strength refractory should provide margin against any potential high stresses leading to excessive deformation and/or failure. The provision for accommodating internal leakage discussed earlier will support a small helium in-leakage to each of the capsules through the bottom through-tube penetrations.

- Thermocouple failures - The combination of spatial constraints, irradiation conditions, material requirements, temperatures and durations of AGR-1 significantly exceed the nominal capabilities of commercially available thermocouples. INL has conducted long-term elevated-temperature testing of candidate commercial thermocouples and high-temperature thermocouples developed at INL. While reinforcing concerns about thermocouple drift, no complete failures were observed and the results provided a basis for selection of thermocouples to be used and their likely performance. Using these results and test train thermal analyses, INL has specified several types, including commercial thermocouples and thermocouples developed at INL, to be placed at specific locations based on expected local temperature conditions and thermocouple performance capabilities, with multiple thermocouples provided for each capsule.

- Gas line failures - Leaks or blockages in a capsule gas supply or return line could impede the ability to control temperature and monitor gas release from the capsule. The gas lines are small $(\sim 1 / 16$ " diameter $)$ and must be fed through the relatively congested capsule through-tubes and out the lead-out tube. Test train mockups are being used to gain experience with the different parts of the assembly, with attention to controlling the minimum gas line and thermocouple lead bend radii to prevent kinking during assembly. Flow capability will be checked during test train assembly.

- Fission product monitor failure - A fission product monitoring system is provided for each capsule to measure the release of fission products during irradiation. If a monitoring system fails, key data from that capsule would be lost. The fission product monitoring system design provides for a seventh spare system that can be valved in to replace the failed system. 
- Graphite fuel specimen holder cracking - The graphite between fuel compacts and between fuel compacts and through-tubes is thin due to space limitations and could be subject to cracking during the irradiation. Depending on the location and extent of cracking, the gap between the holder and the capsule wall could be altered, changing the heat transfer characteristics of the capsule. Analysis results indicate that the fuel compact should shrink more than the fuel holder, precluding failure due to differential shrinkage.

- $\quad$ Chemical attack of fuel test articles - Material investigations have indicated that if stainless steel or Inconel is in direct contact with graphite at elevated temperature, carbides of iron, nickel or chromium can migrate through the graphite into the fuel compact and attack the fuel particle silicon carbide ( $\mathrm{SiC}$ ) layer. In order to avoid this problem, stainless steel or Inconel components in the elevated temperature regions of the capsules have been replaced or sheathed by refractory metals (Mo or $\mathrm{Nb}$ ).

- $\quad$ Temperature control during irradiation - The use of $\sim 19.8 \%$ enriched fuel, as compared with mixtures of fissile and fertile particles or lower enriched German fuel, produces a larger reduction in power during the irradiation due to $\mathrm{U}^{235}$ depletion and lower buildup of plutonium. The large power swing during irradiation would limit the ability to maintain fuel temperatures at desired levels. To flatten the power production, borated graphite was specified for the graphite specimen holder in the capsules. The initial power level is substantially reduced, and depletion of the boron leads to a manageable power variation with peak power occurring between one third and one half of the way through the irradiation.

- $\quad$ Axial power variation - Typical axial power distributions fall off significantly at the top and bottom. The ATR axial thermal flux distribution is relatively flat in the center 30 inches $(76.2$ $\mathrm{cm}$ ) of the core. Additional flattening is obtained by reducing the graphite fuel holder boron concentrations in the top and bottom capsules.

- $\quad$ Azimuthal power variation - The AGR-1 test train is located in an irradiation hole in the ATR reflector, resulting in a significant neutron flux gradient. In order to flatten the azimuthal power variation, a thin hafnium sheet acting as a thermal neutron filter covering a $240^{\circ}$ sector facing the core has been installed in each capsule, while the back $120^{\circ}$ sector uses a stainless steel segment.

- Overpower during PALM cycles - In order to meet the needs of another irradiation client, the ATR is periodically operated in what is referred to as a "PALM cycle" mode. In this mode, the core power level and resulting thermal neutron flux at the AGR-1 test train location is substantially higher. If a PALM cycle occurs near the time of peak power during the AGR-1 irradiation, maximum temperature limits could be exceeded. To limit the power in the capsules during a PALM cycle, provisions have been made to use He-3 in place of normal helium. The high thermal neutron absorption coefficient of He-3 will reduce the power to acceptable levels if a PALM cycle were to be conducted during a portion of the AGR-1 irradiation period of concern. The program will work with ATR operations to attempt to avoid having a PALM cycle during the remaining period.

- $\quad$ Test train contamination following irradiation - Transfer of the test train from the reactor to the canal following irradiation will require cutting the lead-out tube and handling the test train under water. This introduces the possibility of moisture intrusion and degradation of the contents prior to disassembly. Substantial efforts have been directed toward establishing procedures to prevent moisture intrusion during the cutting process and effectively sealing the tube to prevent intrusion in subsequent handling. 
The AGR-1 test train design builds upon the successful design, assembly, and operation of capsules built by INL for previous ATR customers. Many of these challenges have been encountered individually and successfully overcome in other similar types of irradiation capsules developed at INL in the past. The challenge for AGR-1 is that the test train contains many of these challenges simultaneously and under conditions (time, temperature, fluence) that exceed previous fuel irradiation experience in ATR.

\subsection{Fuel Selection and Fabrication}

As noted earlier, the AGR-1 test train has been designed to provide six separately controlled and monitored capsules containing fuel specimens. This capability allows for simultaneous irradiation of multiple fuel types, or simultaneous irradiation of a given fuel type at multiple temperatures. For AGR-1, this capability will be used to irradiate multiple fuel types with the objective of maximizing the prospects of successful performance by at least one fuel, as well as to provide insights into the relationship of key coating process conditions and material properties to fuel performance. A baseline fuel has been specified and produced with the intent of providing the greatest potential for successful performance, and variants (same specification as baseline fuel with the exception of a primary process condition and related properties) have been specified to provide diversity in the areas considered to present the greatest risk of unsuccessful performance of the baseline fuel. The selection of the baseline and variant fuel specifications are briefly summarized in the following discussion.

Prior to the start of the AGR fuel program extensive reviews of fabrication, irradiation and safety testing of US and German fuel had been conducted ${ }^{9,10}$. The results of these studies and discussions among the AGR fuel program participants resulted in the set of fuel failure mechanisms and associated fuel properties identified in Table 3.2 of the Technical Program Plan ${ }^{1}$. This review and discussions among program participants were primary input for establishing revision 0 of the AGR-1 fuel specification, which has evolved to reflect additional understandings gained through subsequent fuel fabrication process and characterization methods development ${ }^{3}$. The fuel specification was predicated upon use of the UCO kernel to achieve the performance requirements of the VHTR while producing coatings that to the extent possible replicated the coatings developed and successfully irradiated in the German program. As fuel characterization methods were reestablished early in the program, representative high performance German fuel particles ${ }^{11}$ and fissile particles from the poorly performing composite irradiated in HRB-2 $1^{12}$ were characterized. The AGR program considered these inputs and other reference material on coated particle fuel performance to identify failure mechanisms and related fuel properties that presented the greatest uncertainty and risk with regard to successful fuel performance.

As a result of these considerations, particular emphasis was placed on irradiation induced dimensional changes in the inner pyrocarbon layer (IPyC), and the resulting induced stresses and potential for $\mathrm{IPyC} / \mathrm{SiC}$ layer debonding and cracking of the IPyC and SiC layers. The primary measured pyrocarbon properties associated with these phenomena are anisotropy, density, and surface connected porosity. It was also recognized that process conditions and properties that led to increased irradiation stability could also lead to increased permeability and dispersion of uranium from the kernel into the buffer and IPyC layers during SiC coating and compact heat treatment. During irradiation the dispersed uranium could lead to chemical attack and degradation of the SiC layer. Thus identification of an optimum IPyC process and product specification involved a tradeoff between these two concerns. In the course of coating process development at ORNL, an experimental study was conducted on the effects of process conditions on these IPyC properties ${ }^{13}$. The results of this study were used to establish IPyC process conditions and properties for the baseline fuel (adjusted slightly to accommodate subsequent additional process development results). Since IPyC performance and attaining an optimum tradeoff between dimensional stability and uranium dispersion was a primary concern, the IPyC study results were also used to define variants 1 and 2, providing diversity of fuel types directly addressing this tradeoff. 
Another area of concern with regard to fuel performance was silicon carbide microstructure. SiC layers of earlier US fuel, which was produced at higher coating temperatures, exhibited large columnar grains (radial dimensions approaching the thickness of the $\mathrm{SiC}$ layer), while German $\mathrm{SiC}$ contained smaller more symmetric grains. There is concern that larger columnar grains may be more susceptible to chemical attack and metallic fission product diffusion along the grain boundaries. Thus the $\mathrm{SiC}$ coating conditions for the baseline and variants 1 and 2 were derived from German conditions available in the open literature. Since $\mathrm{SiC}$ performance in terms of resistance to chemical attack and retention of metallic fission products was also considered an element of significant risk, achieving diversity in the $\mathrm{SiC}$ microstructure was the basis for specifying variant 3. A mixture of hydrogen and argon carrier gas was used in the $\mathrm{SiC}$ coating for variant 3, as compared to a pure hydrogen carrier gas in the baseline and variants 1 and 2 . In conjunction with this change, the $\mathrm{SiC}$ coating temperature was reduced, consistent with ORNL developmental results for $\mathrm{SiC}$ coating using a mixture of hydrogen and argon ${ }^{14}$. In addition to providing diversity in the $\mathrm{SiC}$ microstructure, variant 3 is also expected to have less uranium dispersion in the buffer and $\mathrm{IPyC}$ than the baseline fuel due to the lower $\mathrm{SiC}$ coating temperature.

It was also recognized that $\mathrm{OPyC}$ failures, induced by propagation of failures from the low density pyrocarbon outer layer in the TRISO-P particle design used in HRB-21, were likely a contributing factor in the observed poor performance. Thus the outer low density pyrocarbon layer of the HRB-21 particle design was eliminated.

The program has conducted a systematic fuel fabrication process development effort. Surrogate particles were obtained from commercial suppliers and depleted uranium oxide $\left(\mathrm{DUO}_{2}\right)$, natural uranium oxycarbide (NUCO) and low enriched uranium oxycarbide (LEU UCO) kernels were fabricated to support the development effort. The surrogate and $\mathrm{DUO}_{2}$ kernels were used for early coating process development and later supplementary efforts, while the $\mathrm{NUCO}$ and $\mathrm{DUO}_{2}$ kernels were used for later stage coating process development and LEU UCO was used for production of particles for AGR-1. The LEU UCO kernels produced by BWXT ${ }^{15}$ were characterized ${ }^{16}$ and used to produce coated particles for AGR-1 ${ }^{14}$ which were then characterized ${ }^{17,18,19,20}$ to assure compliance with the AGR-1 fuel specification ${ }^{3}$. Potential fuel failure mechanisms and provisions for addressing them are noted below.

- General failure mechanisms as identified in Table 3.2 of the Technical Program Plan ${ }^{1}$ - This was addressed in general terms by the review of coated particle fuel performance ${ }^{9}$ and incorporation of the results into the AGR-1 fuel specification ${ }^{3}$. Subsequent production of AGR-1 fuel was performed in compliance with the ORNL QA program.

- $\quad \underline{P y C}$ and/or SiC structural failures caused by irradiation induced dimensional changes in the pyrocarbon - Addressing this failure mechanism was a primary focus of adjustments to the AGR1 baseline fuel IPyC and OPyC process and property specifications, based on results of the IPyC study. Specification of changes to IPyC process conditions for variants 1 and 2, also based on results of the IPyC study, to provide diversity of IPyC properties (density, anisotropy, surface connected porosity) that are related to irradiation induced dimensional change.


an investigation of the relationship of IPyC deposition conditions to IPyC permeability and uranium dispersion, and the results were factored into the specification of AGR-1 baseline and variants 1 and 2 fuel. Variant 3, with baseline IPyC conditions, used a reduced $\mathrm{SiC}$ coating temperature, which may reduce uranium dispersion during coating. Also, differences in the variant $3 \mathrm{SiC}$ microstructure resulting from the use of an argon/hydrogen carrier gas mixture in conjunction with a reduced coating temperature may reduce its susceptibility to attack by fission products produced by the dispersed uranium as noted below.

- Diffusion of metallic fission products through the $\mathrm{SiC}$ layer - As noted above, differences in variant $3 \mathrm{SiC}$ coating conditions, relative to those used for the baseline and variants 1 and 2, 
produced a significantly different $\mathrm{SiC}$ microstructure. This difference in $\mathrm{SiC}$ microstructure may reduce the susceptibility of the $\mathrm{SiC}$ layer to fission product attack and metallic fission product diffusion along grain boundaries, providing important diversity among the fuel types with regard to this release mechanism.

- $\mathrm{SiC}$ anomalies - Anomalies at the $\mathrm{IPyC} / \mathrm{SiC}$ interface or within the $\mathrm{SiC}$ can include soot inclusions or microstructure interruptions associated with particle bed fluidization during coating. Soot inclusions, often termed "gold spots" because of their effect on the surface appearance of the $\mathrm{SiC}$ layer, have been observed historically at percent levels and higher. While there is no clear evidence that these anomalies cause particle failures, concerns about possible effects led to the specification of a maximum gold spot fraction of $10^{-3}$ at $95 \%$ confidence. Initial LEU UCO particle batches failed to meet this specification, and considerable process development effort was expended to reach compliance for all the AGR-1 fuel types. Since the characteristics of some of the observed anomalies differed from those typically observed in past US coated particle fuel, additional analyses were conducted to assess their failure probability ${ }^{21}$, indicating expectations of acceptable performance.

- Impurity attack of SiC layer - Attack of the SiC layer by impurities, particularly iron inclusions in the compact matrix, has been observed in prior irradiations. The AGR-1 fuel specification ${ }^{3}$ addressed this issue through maximum impurity limits for the kernels and compacts, and the AGR-1 design requirements ${ }^{5}$ and material specifications ${ }^{22}$ provided impurity limits for the graphite fuel holders. The kernels were found to be within the specifications ${ }^{15}$, while compact impurity results are not yet available as of the writing of this report. Initial results for the graphite fuel holder material found it to significantly exceed the impurity limit, and efforts are ongoing to address this issue by a combination of reduction of the impurities and justification of a nonconformance if necessary.

- $\quad$ Kernel migration - Migration of the kernel under a temperature gradient within the particle could bring the kernel in contact with the $\mathrm{SiC}$ layer resulting in particle failure. Experimental and analytical investigations have shown that a UCO kernel is not subject to kernel migration if sufficient carbon is present. Characterization of the kernels used in the production of AGR-1 fuel indicated that the lower limit of the one-sided $95 \% / 99 \%$ tolerance interval of the $\mathrm{C} / \mathrm{U}$ ratio was 0.157 , less than the specification minimum lower limit of 0.2 . This nonconformance with the AGR-1 specification was analyzed by INL ${ }^{23}$ and is not expected to present a problem with regard to kernel migration even if $\mathrm{C} / \mathrm{U}$ were zero.

- $\quad$ Pressure vessel failure - Release of fission product gases into the buffer, in combination with production of $\mathrm{CO}$ due to excess oxygen released by fissioning in the kernel, could lead to over pressurization and failure of the particle pyrocarbon and silicon carbide layers. Experimental and analytical investigations have shown that carbon in a UCO kernel mitigates excess oxygen and $\mathrm{CO}$ formation if sufficient carbon is present. Characterization of the kernels used in the production of AGR-1 fuel indicated that the lower limit of the one-sided 95\%/99\% tolerance interval of the $\mathrm{C} / \mathrm{U}$ ratio was 0.157 , less than the specification minimum lower limit of 0.2 . This nonconformance with the AGR-1 specification was analyzed by $\mathrm{INL}^{23}$ and is not expected to present a problem with regard to pressure vessel failure even if $\mathrm{C} / \mathrm{U}$ were as low as 0.1 . 


\section{OPERATIONAL CONTINGENCIES}

As discussed in the previous section, the design and fabrication of the AGR-1 test train and fuel specimens have presented many technical challenges. While many provisions have been made to address and mitigate potential failure mechanisms, the risk of failures that could negatively impact the AGR-1 irradiation remains significant. The following operational contingencies are available to address situations that could arise during the course of the irradiation.

- Thermocouple Drift and Failure - Given the service conditions and other technical considerations discussed in the previous section, some degree of thermocouple drift and failure is to be expected in the course of the irradiation. Pre-test predictions will include multi-dimensional thermal analyses of the test train, which can be compared with indicated temperature distributions at the beginning of the irradiation. If necessary, the thermal analyses can be adjusted to better match the indicated initial conditions and temperature data available prior to thermocouple failure, and used to help identify thermocouple drift and support capsule operations. Operational contingencies are discussed below in terms of increasing degree of failure.

- $\quad$ Substantial drift of one or more thermocouples within a capsule - Trends in the relative indications among the multiple thermocouples within a capsule, along with comparison to predicted trends from the 3-D thermal analyses and results from out-of-pile thermocouple testing can be used to identify and estimate the magnitude of drift of a thermocouple. If a control thermocouple is experiencing drift, a bias can be applied to the temperature setpoint or control can be switched to another thermocouple with appropriate adjustment of the control setpoint. It is anticipated that establishing baseline responses for all thermocouples to compare with the detailed 3-D thermal model early in the irradiation prior to irradiation-induced changes in the capsule contents will be most useful to determine thermocouple drift and apply an appropriate bias. Once significant fissile depletion, shrinkage of the graphite and fuel, and changes in the conductivity of the fuel matrix occur, the ability to separate drift from the real thermal response is more difficult. Comparing the 3-D thermal model to the thermocouple responses at one or more fixed gas mixes at the beginning of every cycle will help separate out the effects of drift versus thermophysical and geometric changes in the capsule that will affect the predicted fuel temperature. Because of the large amount of data to be obtained in the capsule (e.g., thermocouple measurements, ATR lobe powers, flow gas mix) INL is evaluating the use of a statistical data analysis program to help in this evaluation and baselining activity.

- Failure of a thermocouple within a capsule - If the failed thermocouple was the control thermocouple, control can be switched to a functioning thermocouple with appropriate adjustment of the control setpoint. Temperature indications prior to failure, in conjunction with the 3-D thermal analysis, can be used to determine the temperature distribution within the capsule.

- $\quad$ Failure of all thermocouples within a capsule - If all thermocouples within a capsule fail, control can be switched to manual with gas mixtures adjusted based on a combination of temperature indications from an adjacent capsule and thermal analyses. Data from the fission product monitor for the capsule may also be used to provide confidence that temperatures are being maintained within the desired range.

- $\quad$ Change in test train internal leakage - A limited amount of leakage flow from the test train common gas space to each of the capsules through the sliding seals at the bottom through-tube penetrations is expected. Helium pressure in the common gas space will be maintained slightly 
higher than the pressure in the capsules to assure in-leakage into the capsules and prevent crosscontamination. If a significant additional leakage path, say failure of a brazed capsule penetration, opened up, an increase in the helium flow would be required to maintain an overpressure in the common gas space. This change plus changes in flow and pressure indications for the leaking capsule should be sufficient to identify that a leak has occurred and to identify the affected capsule. Adjustments to the gas flows to the common space and the affected capsule can be used to mitigate the effect of the leak and prevent cross-contamination between capsules.

- Capsule gas line failure - A leak in a supply or return line to one of the capsules would be more likely to occur during assembly of the capsule, and may be detected and repaired at that time. If a leak were to occur during operation, mitigation actions would depend on whether it was in a supply or return line. Analysis of the exhaust gas and indications from the fission product monitors should allow identification of the affected capsule. Mitigation actions, in terms of adjustments to capsule and common space gas flow, and the impact of the failure would depend on the extent and location of the leak.

- Excessive fuel failures within a capsule - ATR safety requirements can be met with percentage level failures in all of the capsules. However, high failure levels within a capsule, as indicated by the fission gas monitor, may lead to concerns about cross-contamination and loss of data for other capsules, thus continued operation of the high release capsule at the planned temperature level may not be warranted. Gas release levels and the potential for additional particle failures within the capsule can be mitigated by reducing capsule operating temperatures through increasing the helium fraction, and in-flow to the capsule from the common gas space can be increased by reducing capsule pressure through a reduction in capsule gas supply flow. 


\section{REFERENCES}

1. ORNL/TM-2002/262, "Technical Program Plan for the Advanced Gas Reactor Fuel Development and Qualification Program,” April 2003.

2. INL/EXT-05-00465, Rev. 1, "Technical Program Plan for the Advanced Gas Reactor Fuel Development and Qualification Program," August 2005.

3. INL Engineering Design File No. 4380, Rev. 7, "Fuel Product Specification and Characterization Guidance," February 2006.

4. INL Engineering Design File No.4731, Rev. 1, “AGR-1 Irradiation Test Specification,” July 2004.

5. INL Technical and Functional Requirements TFR-249, Rev. 1, "Requirements for Design of the Advanced Gas Reactor Experiment AGR-1 for Irradiation in the Advanced Test Reactor," December 2004.

6. INL Technical and Functional Requirements TFR-248, Rev. 1, "Temperature Control and Off Gas Monitoring Systems for the Advanced Gas Reactor Experiment AGR-1," March 2005.

7. DOE-HTGR-90322, “HRB-21 Irradiation Phase Test Report,” January 1993.

8. DOE-HTGR-100229, "Fuel Capsule HRB-21 Postirradiation Examination Data Report," April 1995.

9. DOE-HTGR-90390, “MHTGR TRISO-P Fuel Failure Evaluation Report,” October 1993.

10. INEEL/EXT-02-00300, "Key Differences in the Fabrication, Irradiation and Safety Testing of U.S. and German TRISO-coated Particle Fuel and Their Implications on Fuel Performance," June 2002.

11. ORNL/CF-04/06, "Results from ORNL Characterization of German Reference Fuel from EUO 23582365 Composite," April 2004.

12. ORNL/CG-04/08, "Results from ORNL Characterization HRB-21 Reference Fuel," August 2004.

13. ORNL/TM-2005/533, "Effects of Deposition Conditions on the Properties of Pyrolytic Carbon Deposited in a Fluidized Bed," September 2005.

14. ORNL/CF-06/02, "Fabrication of Baseline and Variant Particle Fuel for AGR-1," April 2006.

15. BWXT certified data package, "G73 Industrial Fuel Fabrication and Development Lot G73D-2069302," April 2005

16. ORNL/TM-2005/517, "Results from ORNL Characterization of Nominal $350 \mu \mathrm{m}$ LEU UCO Kernels from the BWXT G73D-20-69302 Composite," August 2005.

17. ORNL/TM-2006/019, "Data Compilation for AGR-1 Baseline Coated Particle Composite LEU0146T," April 2006.

18. ORNL/TM-2006/020, "Data Compilation for AGR-1 Variant 1 Coated Particle Composite LEU0147T," April 2006.

19. ORNL/TM-2006/021, "Data Compilation for AGR-1 Variant 2 Coated Particle Composite LEU0148T," April 2006.

20. ORNL/TM-2006/022, "Data Compilation for AGR-1 Variant 3 Coated Particle Composite LEU0149T," April 2006.

21. INL Engineering Design File No. 7109, "Failure Probability Analysis of AGR TRISO-coated Fuel Particles Having a Gold Spot," June 2006. 
22. INL SPC-789, "Specification, Boronated Graphite for AGR-1 Experiment," April 2006.

23. INL Engineering Design File No. 5796, Rev. 0, "Disposition of BWXT Kernel Lot G73D-20-69302," April 2005. 